И. С. Тарбастаева. Роль религии в национальной политике Республики Тува: анализ государственных программ (2013-2020 гг.)

УДК 322.2

DOI: 10.18101/1994-0866-2020-3-11-20

\title{
РОЛЬ РЕЛИГИИ В НАЦИОНАЛЬНОЙ ПОЛИТИКЕ В РЕСПУБЛИКЕ ТУВА: АНАЛИЗ ГОСУДАРСТВЕННЫХ ПРОГРАММ (2013-2020 гг.)
}

\author{
(c) Тарбастаева Инна Семеновна \\ младший научный сотрудник, \\ Институт философии и права СО РАН \\ Россия, 630090, г. Новосибирск, ул. Николаева, 8 \\ inna-tarbastaeva@yandex.ru
}

\begin{abstract}
Аннотация. Рассматривается роль религиозных институтов в государственных программах в сфере национальной политики в Республике Тува в период с 2013 по 2020 г. Автор исследует, каким образом представлено взаимодействие государственных и религиозных институтов в документах, и насколько оно коррелирует с действительной политикой региональных властей. Используется метод теоретического анализа нормативных правовых актов, стратегических документов, а также контекстуальный метод для сопоставления формально заявленного с фактическим положением дел. Эмпирической базой выступили Конституция Республики Тыва 2001 г., Закон Республики Тыва «О свободе совести» от 01.04.95 № 253, Концепция национальной политики Республики Тыва 1998 г., а также региональные программы в сфере национальной политики в период с 2013 по 2020 г. Наиболее подробно роль религиозных организаций как одного из субъектов национальной политики наряду с органами власти и общественными организациями была прописана в Программе 2013-2016 гг. В последующих программах с 2014 до 2020 гг. наблюдается сужение сферы влияния религии на общественную жизнь. Религиозным институтам отводится роль объектов, которые нуждаются в контроле со стороны органов власти во избежание разжигания религиозного экстремизма. При этом их вклад в развитие этнокультурной сферы в республике в динамике возрастает. Автор предлагает, что несоответствие между закрепленной ролью религиозных институтов в программных документах и их фактическим влиянием на этнокультурные процессы отражает общероссийскую тенденцию, когда законодательно провозглашается отделительная модель, а действительно реализуется кооперационная.

Ключевые слова: религия; государственно-конфессиональные отношения; кооперационная модель; национальная политика; региональные программы; Республика Тува; законодательство; традиционные религии; буддизм; международное сотрудничество; индикаторы программы; Ш. Б. Кара-оол.
\end{abstract}

\section{Для цитирования}

Тарбастаева И. С. Роль религии в национальной политике Республики Тува: анализ государственных программ (2013-2020 гг.) // Вестник Бурятского государственного университета. Философия. 2020. Вып. 3. С. 11-20.

\section{Введение}

Согласно Конституции, Россия является светским государством, где действует принцип отделения религиозных объединений от государства. Тем не менее религиозные организации существуют не в отдельном пространстве, а встроены в общественную жизнь: их деятельность регулируется законодательством, и 
они зачастую выступают активными участниками социальных преобразований. Светский характер государства не отменяет сам факт взаимодействия между институтами управления и духовными центрами.

По оценкам экспертов, с конца 90-х гг. в России наблюдается трансформация государственно-конфессиональных отношений в сторону кооперационной модели, когда происходит сотрудничество религиозных объединений и государства в решении социальных проблем. Хотя формально де-юре закреплена отделительная модель, предполагающая взаимное невмешательство во внутренние дела [1; 2]. Сложившаяся на практике кооперационная модель характеризуется неравенством религий, выделением среди них «традиционных» и «нетрадиционных», предоставлением привилегий избранным религиозным объединениям [3].

Одновременно с этим происходит переформатирование национальной политики в сторону формирования российской нации, укрепления гражданской идентичности [4]. На федеральном и региональных уровнях принимаются соответствующие программы, в которых затрагиваются отдельные аспекты взаимодействия институтов государства и религии в сфере национальной политики. Учитывая это, представляется значимым выявить, какая роль отводится, согласно региональным программам, религиозным институтам в процессе реализации современной национальной политике. В качестве эмпирической базы выступает Республика Тува, в которой начиная с 1990-х гг. идут активные процессы религиозного возрождения, прежде всего, традиционной для тувинцев религии - буддизма.

Материалы и методы исследования. В настоящей работе применяется метод теоретического анализа документов как важнейшего метода сбора информации о государственных целевых установках. Данный метод позволяет приблизиться к пониманию логики власти, определить основные ориентиры в проводимой политике. Вместе с этим используется контекстуальный метод, позволяющий сопоставить формально заявленное с фактическим положением дел и тем самым выявить возможные законодательные пробелы, прояснить действительные направления деятельности органов власти в сфере взаимодействия с религиозными институтами.

Материалами для исследования послужили: Конституция Республики Тува 2001 г., Закон Республики Тува «О свободе совести» от 01.04.95 № 253, Концепция национальной политики Республики Тува 1998 г. Также региональные программы в сфере национальной политики: республиканская целевая программа «Национально-культурное развитие народов Республики Тыва на 2013-2016 годы», государственные программы Республики Тува «Укрепление гражданского единства и национально-культурное развитие народов Республики Тыва на 2014-2016 годы», «Укрепление гражданского единства и национально-культурное развитие народов в Республике Тыва на 2017-2019 годы» и ныне действующая «Укрепление гражданского единства и национально-культурное развитие народов в Республике Тыва на 2018-2020 годы».

Результаты исследования. Согласно ст. 25 Конституции Республики Тува, каждому гарантируется свобода совести, свобода вероисповедания, включая право исповедовать индивидуально или совместно с другими любую религию или не исповедовать никакой, свободно выбирать и менять, иметь и распространять религиозные и иные убеждения и действовать в соответствии с ними. В ч. 1 ст. 26 
И. С. Тарбастаева. Роль религии в национальной политике Республики Тува: анализ государственных программ (2013-2020 гг.)

говорится: на территории Республики Тыва не допускаются пропаганда или агитация, возбуждающие социальную, расовую, национальную или религиозную ненависть и вражду. Запрещается пропаганда войны, а также социального, расового, национального, религиозного или языкового превосходства ${ }^{1}$. Данные нормы являются стандартными и соответствуют духу федеральной Конституции. В них гарантируется, прежде всего, защита прав человека и обеспечение безопасности государства.

Следующий нормативный правовой акт, регулирующий религиозную сферу, это Закон Республики Тыва № 253 «О свободе совести» от 1 апреля 1995 г. В ст. 1 дается определение религии: «Одна из форм общественного сознания, являющаяся совокупностью мистических представлений, покоящихся на вере в сверхъестественные силы и существа, которые являются объектом поклонения» ${ }^{2}$. В этой же статье ниже приводится закрытый перечь традиционных для республики религий: «На территории Республики Тыва к традиционным конфессиям относятся шаманизм, буддизм и православие» ${ }^{3}$. Это интересная особенность данного регионального закона, когда власть напрямую выстраивает иерархию между религиями, выделяя одни и оставляя как бы за скобками другие. Остается неясным, в чем разница между традиционными конфессиями и нетрадиционными с точки зрения закона. Как это положение должно сказываться, скажем, на мигрантах-мусульманах из Средней Азии? Если никак, тогда в чем его смысл? Можно предположить, что региональная власть таким образом пыталась придать официальный статус буддизму и шаманизму как древним верованиям, которые исповедовались тувинцами испокон веков. Скорее всего, православие здесь указывается в чисто дипломатических целях, поскольку еще в начале $\mathrm{XX}$ в. христианская миссия была фактически провалена на территории республики - последователей было крайне мало. Хотя в настоящее время ситуация изменилась, и православие более основательно утвердилось в регионе.

Надо сказать, что Тува здесь не исключение. Есть примеры, когда на уровне республиканских законов власти пытаются подчеркнуть наиболее традиционные верования народов. Так, в законе Татарстана «О свободе совести и о религиозных объединениях» от 14 июля 1999 г. № 2279 в преамбуле говорится: «признавая особую роль ислама и православия в становлении и развитии духовности и культуры многонационального народа Татарстана» ${ }^{4}$.

Вернемся к рассматриваемому закону Тувы. В ст. 4.1 дается определение святых (священных) мест: «расположенные на территории Республики Тыва, яв-

${ }^{1}$ Конституция Республики Тыва (с изменениями на: 12.04 .2019$)$ // Тувинская правда. 2012. № 72.10 июля.

${ }^{2} \mathrm{O}$ свободе совести и религиозных организациях: закон Республики Тыва от 01.04.95 № 253 (ред. от 22.06.05) (принят Верховным Хуралом Республики Тыва 16.03.95) [Электронный ресурс] // Правовой фонд электронной и нормативно-технической документации. URL: http://docs.cntd.ru/document/802048821 (дата обращения: 04.05.2020).

${ }^{3}$ Там же.

${ }^{4}$ О свободе совести и о религиозных объединениях: закон Республики Татарстан (с изменениями на 7 марта 2020 года) от 28.08.1999 № 17 // Республика Татарстан. 1999. № 174. 28 авг. 
ляющиеся объектами поклонения и почитания верующими, в которых совершаются религиозные обрядовые действия, в том числе природные объекты (горы, перевалы, деревья, родники, ключи и другие)». Данная норма не просто формальность, а действительно отражает устойчивые социальные практики современных тувинцев, связанные с поклонением природе (духам местности и др.). Важно, что законодательно закреплены в том числе и природные объекты; это может пригодится в случае их правовой охраны в спорных вопросах, когда сталкиваются интересы бизнеса и культуры народа. В остальном данный закон воспроизводит стандартные нормы регулирования деятельности религиозных институтов, очерчивая им правовые границы дозволенного.

В 1988 г. была принята Концепция национальной политики Республики Тыва (далее - Концепция). Это интересный и содержательный документ, в котором прослеживается учет локальной специфики, а также в значительной степени самостоятельность региональных властей в области реализации национальной политики [5]. Это проявилось и в отношении религиозной сферы.

Согласно духу времени, в Концепции является фиксация проблема: «в 3050-е гг. XX в. ущемлялись права и свободы людей, особенно верующих. Были подорваны хозяйственные, организационные и кадровые основы развития религий» ${ }^{1}$. Как пишет тувиновед М. В. Монгуш, «на начальном этапе постсоветской истории Тувы национальные лидеры в своих выступлениях активизировали только те слои исторической памяти, которые содержали воспоминания об ущемлении прав тувинцев в советское время, проводившуюся русификацию и перегибы в национальной политике» [6, с. 193].

В Концепции закреплялись такие принципы, как равенство прав и свобод человека и гражданина независимо от его отношения к религии, запрещение любых форм ограничения прав граждан по признакам религиозной принадлежности, запрещение пропаганды и агитации, а также деятельности лиц и организаций, направленных на разжигание религиозной розни, учет взаимосвязи национальных обычаев, традиций и обрядов с религией, поддержка усилий религиозных организаций в миротворческой деятельности ${ }^{2}$.

Одной из задач Концепции провозглашалось «достижение и поддержание стабильности межэтнического и межконфессионального согласия» ${ }^{3}$. Гарантировалось право граждан «участвовать в культурном сотрудничестве народов, этнических и религиозных общин, отправлять религиозные обряды; участвовать и поддерживать без какой-либо дискриминации свободные и мирные контакты через границы с гражданами других государств, с которыми они связаны историческими, национальными, религиозными, родственными и языковыми узами» ${ }^{4}$.

${ }^{1}$ Об утверждении концепции государственной национальной политики Республики Тыва. Президент Республики Тыва. Указ от 22 апреля 1998 года № 217 [Электронный ресурс] // Правовой фонд электронной и нормативно-технической документации. URL: http://docs.cntd.ru/document/906701133 (дата обращения: 04.05.2016).

${ }^{2}$ Там же.

${ }^{3}$ Там же.

${ }^{4}$ Там же. 
И. С. Тарбастаева. Роль религии в национальной политике Республики Тува: анализ государственных программ (2013-2020 гг.)

В Концепции указывалось, что республика «в области международных и внешнеэкономических связей устанавливает и поддерживает дружественные контакты религиозных и общественных объединений с соответствующими структурами зарубежных стран» ${ }^{1}$. Данное положение было особенно важным, поскольку для возрождения буддизма необходимо было устанавливать контакты с международными организациями, прежде всего, с крупными буддийскими монастырями в Индии. За годы советской власти существенно ухудшилось качество аутентичных буддийских знаний у местных лам, и требовалось восстановить их уровень образования. С 1996 г. начался первый поток тувинских монахов в монастырь Дрепунг Гоман в Индии [7].

В целом закрепленные в Концепции положения, касающиеся религии, отвечали задачам своего времени и способствовали духовному возрождению тувинского общества. В 1990-е гг. со стороны региональных властей были проявлены серьезные усилия с целью религиозно-нравственного подъема народа, который в дальнейшем укрепил позиции религиозных институтов.

Следующий период начинается с принятия в 2013 г. федеральной Стратегии государственной национальной политики ${ }^{2}$. В Туве были приняты четыре соответствующие государственные программы: «Национально-культурное развитие народов Республики Тыва на 2013-2016 годы», «Укрепление гражданского единства и национально-культурное развитие народов Республики Тыва на 2014-2016 годы», «Укрепление гражданского единства и национально-культурное развитие народов в Республике Тыва на 2017-2019 годы» и ныне действующая «Укрепление гражданского единства и национально - культурное развитие народов в Республике Тыва на 2018-2020 годы».

Наиболее подробно роль религиозных организаций как одного из акторов национальной политики наряду с органами власти и общественными организациями была прописана в Программе 2013-2016 гг. Одной из целей являлось: «объединение усилий органов госвласти республики и местного самоуправления, общественных национальных и религиозных объединений для сохранения межнационального согласия, гармонизации межнациональных отношений» ${ }^{3}$. В качестве задач обозначалось: «совершенствование механизмов основных направлений религиозной национальной политики» ${ }^{4}$.

${ }^{1}$ Об утверждении концепции государственной национальной политики Республики Тыва... URL: http://docs.cntd.ru/document/906701133 (дата обращения: 04.05.2016).

2 O внесении изменений в Стратегию государственной национальной политики Российской Федерации на период до 2025 года, утвержденную Указом Президента Российской Федерации от 19 декабря 2012 г. № 1666: указ Президента Российской Федерации [Электронный ресурс] // Гарант.ру. Информационно-правовой портал. URL: http://base.garant.ru/70284810/ (дата обращения: 13.02.2020).

${ }^{3}$ Об утверждении республиканской целевой программы «Национально-культурное развитие народов Республики Тыва на 2013-2016 годы» (Утратил силу на основании Постановления от 8 октября 2013 года № 584) [Электронный ресурс] // Правовой фонд электронной и нормативно-технической документации. URL: http://docs.cntd.ru/document/ 430502436 (дата обращения: 04.05.2020).

4 Там же. 
В последующей Программе 2014-2016 гг. религиозные институты уже выступают не в качестве субъектов национальной политики, а только как объекты, на которые воздействует государство. Так, в мероприятиях по реализации данной Программы указывался мониторинг реализации комплексного учебного курса «Основы религиозных культур и светской этики», поддержка электронных и печатных СМИ, ориентированных на религиозную толерантность, поддержка волонтерского движения по восстановлению памятников истории, включая религиозные комплексы, оказание содействия участию представителей религиозных объединений в международных мероприятиях ${ }^{1}$. В Программе 2017-2019 гг. эта тенденция сохраняется, и к мероприятиям добавляется «вовлечение религиозных организаций в деятельность по установлению межнационального диалога» ${ }^{2}$.

В Программе 2018-2020 гг. религиозные институты также не фигурируют как акторы национальной политики, но заметно усиление внимания к религиозной сфере как потенциальному источнику конфликтов. В целях программы указывается гармонизация межнациональных и межконфессиональных отношений, а также профилактика экстремизма на национальной и религиозной почве ${ }^{3}$. В мероприятиях программы появляется деятельность по созданию видеороликов, направленных на профилактику религиозного экстремизма, проведение психолого-религиоведческих экспертиз, а также профилактика религиозно-политического экстремизма. Представляется, что данные положения появились во имя реализации законодательства по профилактике экстремистской деятельности.

В Программе 2018-2020 гг. упущено нескольких важных моментов. Во-первых, в отличие от Концепции 1988 г., в документе отсутствуют положения о международном сотрудничестве с религиозными организациями. Это важный момент, поскольку для развития буддизма по-прежнему значимо взаимодействие с крупными индийскими монастырями как образовательными центрами для продолжения подготовки местных квалифицированных лам. Кроме этого, у местных мирян также есть большая потребность в получении учения у своего духовного учителя Его Святейшества Далай-Ламы XIV, который в настоящее время проживает на территории Индии. Российское правительство на протяжении нескольких последних лет отказывает ему в выдаче визы вследствие внешнеполитических причин, а именно неразрешенности китайско-тибетского вопроса [8]. Ч. К. Ламажаа называет Его Святейшество Далай-Ламу XIV «персональным центром геокультурного

${ }^{1}$ Об утверждении государственной программы Республики Тыва «Укрепление гражданского единства и национально-культурное развитие народов Республики Тыва на 2014-2016 годы» (Утратил силу на основании Постановления Правительства РТ от 29.11.2016 № 515) [Электронный ресурс] // Правовой фонд электронной и нормативнотехнической документации. URL: http://docs.cntd.ru/document/430502436 (дата обращения: 04.05.2020).

2 Там же.

${ }^{3}$ Об утверждении государственной программы Республики Тыва «Реализация государственной национальной политики Российской Федерации в Республике Тыва на 2018-2020 годы» (Утратил силу на основании Постановления от 23.04.2020 Г. № 174) [Электронный ресурс] // Правовой фонд электронной и нормативно-технической документации. URL: http://docs.cntd.ru/document/446646615 (дата обращения: 04.05.2020). 
И. С. Тарбастаева. Роль религии в национальной политике Республики Тува: анализ государственных программ (2013-2020 гг.)

образа мирового буддизма» и подчеркивает, что «буддийский мир воспринимается в первую очередь не в связи с определенной локализацией, а в связи с деятельностью его лидера» [9, с. 35]. Поэтому невозможность тувинцев напрямую получать наставления от Учителя в России воспринимается ими как серьезная проблема и вынуждает выезжать на его лекции в соседние страны, что могут позволить себе далеко не все верующие из-за тяжелой экономической обстановки в регионе.

Во-вторых, в целевых индикаторах эффективности действующей Программы нет показателей, отражающих ситуацию в сфере гармонизации межрелигиозных отношений. В целом регион отличается спокойными неконфликтными межрелигиозными взаимодействиями: в обществе сложились устойчивые практики, когда люди могут одновременно обращаться за помощью как к буддийским ламам, так и к шаманам. Потенциальная напряженность может возникать по линии трудовых мигрантов из Средней Азии, которые исповедуют нетрадиционную для региона религию ислам, а также ее может спровоцировать возрастающее «влияние новых, преимущественно протестантских религиозных направлений, ранее не имевших распространения в республике» [6, с. 204]. Возможно, в Программу следует добавить следующий показатель: «доля граждан, отмечающих отсутствие в отношении себя дискриминации по признакам религиозной принадлежности (в процентах)».

Обсуждение и заключение. Проведенный анализ позволяет сделать следующие выводы. Напомним, что задача исследования заключалась в том, чтобы посмотреть, какая роль в программах региональной национальной политики отводится религиозным институтам в Туве, где очевиден рост религиозной активности населения [10, с. 70-71]. На законодательном уровне наблюдается сужение сферы влияния религии на общественную жизнь. Если в программных документах 20082013 гг. религиозные институты выступали преимущественно как субъекты национальной политики, то в последующих им отводится роль объектов, которые нуждаются в контроле со стороны органов власти во избежание разжигания религиозного экстремизма.

Вместе с тем вклад религиозных организаций в развитие этнокультурной сферы, которая связана с устойчивыми религиозными традициями, возрастает за счет увеличения ресурсов самих организаций. Так, возрастающий интерес местного населения не просто к обрядовой стороне, а к изучению философских аспектов буддийского учения [9, с. 194-195] позволяет говорить о реализации задачи по «этнокультурного развитию многонационального народа Республики Тыва» ${ }^{1}$.

Итак, выявлено несоответствие между формальной ролью религиозных институтов в сфере национальной политики, зафиксированной в программных документах, и их фактическим вкладом в поддержание этнокультурного многообразия

${ }^{1}$ Об утверждении государственной программы Республики Тыва «Реализация государственной национальной политики Российской Федерации в Республике Тыва на 20182020 годы»: (Утратил силу на основании Постановления от 23.04.2020 г. № 174) [Электронный ресурс] // Правовой фонд электронной и нормативно-технической документации. URL: http://docs.cntd.ru/document/446646615 (дата обращения: 04.05.2020). 
за счет сохранения духовных традиций. По сути, в республике они выступают одними из активных участников процесса по укреплению гражданского и духовного единства российских народов.

Кроме этого, программы в сфере национальной политики в Республике Тува, принятые в 2013-2020 гг., не отражают реальной практики взаимодействия органов государственной власти с религиозными институтами. Действующий глава региона уделяет особое внимание процессам религиозного возрождения в республике, и это имеет прямое отношение к региональной национальной политике. Ш. Б. Кара-оол лично встречает высоких тибетских лам, приезжающих в республику с лекциями, проводит с ними официальные встречи в правительстве, выступает на их лекциях с благодарственными словами, курирует строительство религиозных объектов, призывает буддистов в социальных сетях придерживаться нравственного образа жизни, согласно учению, вникает в вопросы обучения местных лам в крупных монастырях, а также публично транслирует толерантное отношение к православию (ежегодно ныряет в прорубь, поздравляет епископа и др.). Нельзя сказать, что его действия носят формальный характер, скорее всего, они действительно направлены на повышение социальной значимости религии в обществе, актуализацию ее нравственного потенциала среди молодежи. Надо сказать, что задал эту тенденцию еще первый руководитель республики Ш. Д. Ооржак (1992-2007). Как верно отмечает М. В. Монгуш, «республиканские руководители всех уровней вместо правительственных трибун стали занимать почетное место в буддийских и православных храмах. Возможно, официальные власти интуитивно чувствуют потребность в новой общенациональной идее для Тувы взамен коммунистической. И пока не находят ничего лучшего, чем идея духовного возрождения путем обращения к традиционным ценностям духовной культуры» [6, с. 204].

В заключение отметим, что на федеральном уровне нет полноценной концепции государственно-конфессиональной политики [11], соответственно нет четкой официальной роли религии в сфере национальной политики. Сложившаяся ситуация в Республике Тува в виде несоответствия между закрепленной ролью религиозных институтов в программных документах и их фактического влияния на этнокультурные процессы отражает общероссийскую тенденцию: законодательно провозглашается отделительная модель, а действительно реализуется кооперационная [1, с. 103]. Религиозная сфера особенно чувствительная, и властям важно проявлять гибкость в сотрудничестве с соответствующими объединениями, чтобы, с одной стороны, не потерять светский характер государственности, а с другой грамотно использовать гуманистический потенциал религии с целью укрепления духовной общности многонационального народа России.

\section{Лuтература}

1. Мухаметзянова-Дуггал Р. М. Религия и власть в России в XX-XXI вв.: три модели государственно-конфессиональных отношений // Власть. 2017. № 6. С. 100-104.

2. Мирошникова Е. М., Сгибнева О. И. Религиозная политика светского государства в условиях религиозного многообразия // Logos et Praxis. 2017. № 3. C. 62-73.

3. Каневский К. Г. Правовое регулирование государственно-конфессиональных отношений в Российской Федерации: дис. ... канд. юр. наук. М., 2004. 180 с.

4. Тишков В. А. Российский народ: пространство и культура. СПб.: СПбГУП, 2018. $32 \mathrm{c}$. 
И. С. Тарбастаева. Роль религии в национальной политике Республики Тува: анализ государственных программ (2013-2020 гг.)

5. Тарбастаева И. С. Правовое поле этнонациональной политики в Республике Тыва (1991 - наст. вр.) [Электронный ресурс] // Новые исследования Тувы. 2016. № 2. URL: http://nit.tuva.asia/nit/article/view/98 (дата обращения: 10.05.2020.).

6. Монгуш М. В. Конфессиональная ситуация в постсоветской Туве // Acta Slavica Iaponica. 2009. Tomus 26. C. 191-204.

7. Тензин Ч. М.-Х. Буддизм в духовной жизни тувинского общества // Вестник Бурятского государственного университета. 2018. Т. 1, № 3. С. 87-93.

8. Гарри И. Тибетский вопрос и тибетский буддизм в Китае: реформы и конфликты // Государство, религия, церковь в России и за рубежом. 2016. № 4. С. 148-173. DOI: 10.22394/2073-7203-2016-34-4-148-173.

9. Ламажаа Ч. К. Геокультурные образы буддийского мира тувинцев: исторический контекст и современность [Электронный ресурс] // Новые исследования Тувы. 2019, № 3. URL: https://nit.tuva.asia/nit/article/view/862 (дата обращения: 10.05.2020.). DOI: 10.25178/nit.2019.3.3

10. Анайбан 3. В., Тюхтенева С. П. Этнокультурная адаптация населения Южной Сибири (современный период). М.: Институт востоковедения. 2008. 217 с.

11. Верещагин И. Ф. Региональное законодательство о государственно-конфессиональной политике (на примере Архангельской области) // Вестник Северного (Арктического) федерального университета. Серия: Гуманитарные и социальные науки. 2015. № 6. C. $48-58$.

Статья поступила в редакичю 24.08.2020; одобрена после рецензирования 25.09.2020; принята к публикации 24.08.2020.

\section{ROLE OF RELIGION IN NATIONAL POLICY OF THE REPUBLIC OF TYVA: THE ANALYSIS OF GOVERNMENT PROGRAMS (2013-2020)}

Inna S. Tarbastaeva

Junior Researcher,

Institute of Philosophy and Law SB RAS

8 Nikolaeva St., Novosibirsk 630090, Russia

inna-tarbastaeva@yandex.ru

Abstract. The article deals with the role of religious institutions in government programs relating to national policy of the Republic of Tyva over the 2013 to 2020 period. We have considered the way in which the interaction of governmental and religious institutions is presented in the documents, and its correlation with the actual policy of the regional authorities. To compare the state of affairs on paper with facts on the ground we used the method of the contextual method, as well as the theoretical analysis of laws, regulations, and strategic documents. The empirical basis for research was the Constitution of the Republic of Tyva (2001), Law of the Republic of Tyva No. 253 "On Freedom of Conscience" of April 1, 1995, the Concept of National Policy of the Republic of Tyva (1998), as well as regional programs in the field of national policy over the 2013 to 2020 period. Great significance of religious organizations as one of the subjects of national policy along with the authorities and public organizations was spelled out in the program of 2013-2016. In the programs of 2014-2020 there is a narrowing of the sphere of influence of religion on public life. Religious institutions are assigned the role of objects that need to be monitored by the authorities in order to avoid incitement of religious extremism. At the same time, the contribution of government programs to the development of the ethnocultural sphere in the 
republic is growing in dynamics. We suggest that the discrepancy between the fixed role of religious institutions in program documents and their actual impact on ethnocultural processes reflects the all-Russian tendency, when a separate model is proclaimed by law, but a cooperative one is actually implemented.

Keywords: religion; government-religious relationship, cooperation model; national policy; regional programs; the Republic of Tuva; legislation; traditional religions; Buddhism; international cooperation; program indicators; Sh. B. Kara-ool. 